\title{
Performance of Indian diabetes risk score in Southern Karnataka Plateau rural population
}

\author{
Authors \\ Dr Prasanna Kumar $\mathbf{N}^{1}$, Dr Sasi Sekhar ${ }^{2}$, Dr Bhoomika. $\mathbf{V}^{3}$, Dr Dheeraj ${ }^{4}$ \\ ${ }^{1}$ Assistant Professor, General Medicine, SDUAHER \\ ${ }^{2}$ Postgraduate student, General Medicine, SDUAHER \\ ${ }^{3}$ Postgraduate student, Community Medicine, SDUAHER \\ ${ }^{4}$ Postgraduate student, General Medicine, SDUAHER
}

\section{Introduction}

Diabetes, is a major lifestyle disorder, has become a global burden. As of 2019, according to WHO approximately 463 million adults (20-79 years) are living with diabetes; by 2045 this will rise to 700 million. Out of which $79 \%$ of adults with diabetes are living in low- and middle-income countries ${ }^{1}$. India has become one of the epicenters of the global diabetes mellitus pandemic. Rapid socioeconomic development and demographic changes, along with increased susceptibility for Indian individuals, have led to the explosive increase in the prevalence of diabetes mellitus in India over the past ${ }^{2}$. In IDF data as of 2019, 77 million people are affected by diabetes and the number going double by $2045^{3}$. Changing the pattern of epidemiology of diabetes and meeting of rural-urban difference of incidence of the explosive growth of diabetes put the health-care system at stake ${ }^{4}$.

Primary health-care practitioners in low-income countries do not have access to the basic technologies needed to diagnose diabetes at primary level. Only one in three low and middleincome countries report that the most basic technologies for diabetes diagnosis and management are generally available in primary health-care facilities ${ }^{4}$. The problem is further compounded by the fact that $66 \%$ of Indian Diabetics are not diagnosed as compared to $50 \%$ in Europe and $33 \%$ in USA ${ }^{5}$. To intervene, one requires a cost-effective reasonably handy tool to assess the risk of people, pertaining to diabetes. Many health professional organizations in the world have prepared risk assessing tools for predicting the risk of diabetes. Data to support the use of risk scores in screening programs to detect people with prediabetes and undiagnosed diabetes in low- and middle-income countries are limited ${ }^{6}$. The Indian Diabetes Risk Score (IDRS), a simple screening tool for prediction of undiagnosed diabetes developed by Dr. Mohan and colleagues at the Madras Diabetes Research Foundation (MDRF), Chennai. The advantage of IDRS are its simplicity, low cost and is easily applicable for mass screening ${ }^{7}$.

Kolar, is a unique place which shares border with two different states and demographically we get to see people of different lifestyle which influences factors such as differences in diet, physical 
activity and mental stress. Even though it is lying in proximity to state capital, it still largely consists of rural population. The access to healthcare in rural areas still remains a huge challenge. Our study was intended to assess a risk score which is simple, cost effective and economical for the study of larger rural population. In this study we evaluated the performance of IDRS in a rural population of Kolar.

\section{Aim of the Study}

To assess the validity of Indian diabetes risk score in south Karnataka plateau rural population.

\section{Objectives}

1. To assess the performance of IDRS score as screening tool for diabetes

2. To assess the prevalence of diabetes in study population

\section{Method}

This study was conducted in department of medicine, R. L. Jalappa hospital \& research centre, tamaka from December 2018 to December 2019. All individual's $>18$ years of age willing to participate in study were included.

Sample population: people visiting outpatient blocks, wards and patient attendants Exclusion Criteria: Severe co-morbid illness, steroid intake, known cases of diabetes.

\section{Methodology}

A written consent was obtained from all the individuals who underwent fasting plasma glucose estimation. Indian Diabetes risk Score was obtained from all individuals. Then all individuals were tested for fasting (minimum $8 \mathrm{hr}$ fasting) plasma glucose level using venous blood sample in Fluoride vial. Sample was processed. Diagnosis of diabetes is based on American diabetes association 2007 criteria: Fasting blood glucose $126 \mathrm{mg} / \mathrm{dl}$. Abdominal girth was measured at the mid-point between the lowest rib and the highest point of iliac crest using a non-stretchable measuring tape. Age and family history of each individual was noted. The data which was obtained and validity of Indian diabetes risk score in predicting the risk of developing diabetes were assessed. One work sheet was made that included patient particulars like age, sex, brief history, general examination, Risk Score and blood sugar estimation.

\section{Results}

Out of 227 subjects, 55\% (125) were male and $45 \%$ (102) were females. $19 \%$ (43) people were less than 35 years, $30 \%$ (68) were between the age of $35-49$ years and $51 \%$ (116) were having age of $>50$ years. $11 \%$ people were doing sedentary work or no physical activity where as $63 \%$ people were performing regular physical activity and $26 \%$ were doing regular strenuous physical activity. In our study 33 (14.5\%) people diabetes (FBS >/= $126 \mathrm{mg} / \mathrm{dl}$ ) and $49(21.5 \%)$ people with prediabetes (FBS 100-125 mg/dl). Table 1 shows Indian diabetes risk score ${ }^{7}$. Table 2 shows classification of study population according to IDRS.

\section{Table 1}

\begin{tabular}{|l|c|}
\hline \multicolumn{2}{|l|}{ Indian Diabetes Risk Score - IDRS } \\
Particulars Score & Score \\
\hline Age [years] & 0 \\
Age & 20 \\
$<35$ & 30 \\
$35-49$ & \\
$>50$ & Score \\
\hline Abdominal obesity [cm] & 0 \\
Waist size & 10 \\
$<80$ in female, $<90$ in male & 20 \\
$80-89$ in female, $90-99$ in male & \\
$>90$ in female, $>100$ in male & Score \\
\hline Physical activity & 0 \\
Activity & 20 \\
Exercise [regular] + strenuous work & 30 \\
Exercise[regular] or strenuous work & \\
No exercise and sedentary work & Score \\
\hline Family history & 0 \\
Family history & 10 \\
No family history 0 & 20 \\
Either parent 10 & \\
Both parents 20 & \\
\hline
\end{tabular}

\section{Table2}

\begin{tabular}{|l|c|c|}
\hline IDRS & Frequency & percentage \\
\hline Low risk (0-29) & 16 & 7 \\
Moderate risk (30-59) & 145 & 64 \\
High risk (>60) & 66 & 29 \\
\hline Total & 227 & 100 \\
\hline
\end{tabular}


Table no. 3 shows categorization of patients according to the IDRS risk score and number of diabetics among them. In our study majority of diabetes 25 out of 33 total diabetes cases was found with IDRS of $>/=60.8$ out of 33 had IDRS of $<50$ score.

\section{Table 3}

\begin{tabular}{|l|c|c|c|}
\hline score & $\begin{array}{c}\text { no. of } \\
\text { persons }\end{array}$ & percentage & $\begin{array}{c}\text { Total Diabetes } \\
\text { cases }\end{array}$ \\
\hline 10 & 227 & $100 \%$ & 33 \\
\hline 20 & 223 & $98 \%$ & 33 \\
\hline 30 & 211 & $93 \%$ & 33 \\
\hline 40 & 186 & $82 \%$ & 33 \\
\hline 50 & 133 & $59 \%$ & 30 \\
\hline 60 & 66 & $29 \%$ & 25 \\
\hline 70 & 24 & $11 \%$ & 11 \\
\hline 80 & 4 & $2 \%$ & 1 \\
\hline
\end{tabular}

Table no. 4 shows Sensitivity, Specificity, Positive Predictive Value (NPV), Negative Predictive Value (NPV) calculated for each risk score category. Higher IDRS risk score increased the specificity but decreased the sensitivity and lower IDRS risk score increased the sensitivity but decreased the specificity.

\section{Table 4}

\begin{tabular}{|l|c|c|c|c|}
\hline Score & Sensitivity & Specificity & PPV & NPV \\
\hline 10 & 100 & 0 & 14.5 & 0 \\
\hline 20 & 100 & 2 & 14.8 & 100 \\
\hline 30 & 100 & 8 & 15.6 & 100 \\
\hline 40 & 100 & 21 & 17.7 & 100 \\
\hline 50 & 91 & 41 & 22.5 & 96.8 \\
\hline 60 & 73 & 78 & 36.4 & 94.4 \\
\hline 70 & 36 & 94 & 50 & 94.3 \\
\hline 80 & 3 & 98 & 25 & 85.6 \\
\hline
\end{tabular}

\section{Discussion}

Our study comprised of 227 random people visited our institution from rural areas of southern Karnataka, out of which the IDRS risk score found to be Low risk 7\%, Moderate risk 64\%, high risk 29\%. A study conducted by $\mathrm{S}$. Nandeshwar et $\mathrm{al}^{11}$ in Bhopal showed that $2.80 \%$ were in low risk, $28.40 \%$ in moderate risk and $68.80 \%$ were in high risk group as per the IDRS.

The prevalence of undiagnosed cases of diabetes mellitus was reported among 33 (14.5\%). Gupta et $\mathrm{al}^{10}$ their study found the prevalence of diabetes in studied rural population was $5.99 \%$. The difference in the prevalence can be attributed to higher age of study population $51 \%$ with $>50$ years of age where as in their study the number of the subjects $(50 \%)$ were below 35 years of age. Results in different studies vary depending upon the population profile, socio cultural practices, dietary habits.

Sensitivity of IDRS score of 60 was found to be $73 \%$ and Specificity was 78\%; Positive Predictive value was $36.4 \%$ and Negative Predictive Value was $94.4 \%$ among our study participants (table. 4).Our study had similar sensitivity and specificity results of landmark CURES study by Mohan et al ${ }^{7}$ with $72.5 \%$ and $60.1 \%$ respectively. Chaturvedi et $\mathrm{al}^{12}$ in their study the IDRS score of 60 or above, found sensitivity of $65.79 \%$, specificity of $73.91 \%$, PPV of $45.45 \%$, NPV $86.73 \%$. In a study conducted by Adhikari et $\mathrm{al}^{8}$ using an IDRS score $\geq 60$, the sensitivity of $62.2 \%$ in detecting undiagnosed diabetes in that population, with a specificity of $73.7 \%$ which is similar to our study. In another study by Bala $\mathrm{S}$ et al ${ }^{9}$ among urban women Sensitivity of IDRS for a score of 60 or more was found to be $59.4 \%$ and Specificity was $37.3 \%$; Positive Predictive value was $20.4 \%$ and Negative Predictive Value was $77.2 \%$.

\section{Conclusion}

IDRS is a simple, cost effective and economical tool especially in resource constrained rural areas. It can be used for mass screening of the high risk individual of diabetes, so that early interventions for modifiable risk factors can be done at an earliest to prevent further complications such as metabolic syndrome and cardiovascular diseases. Limitations of our study are Sample size which is small, Study was conducted in hospital setting, only people who visited hospital were included in the study. It is not representative of the entire rural adult populations. Due to considerable ethnic and cultural heterogeneity, further studies with larger sample sizes are required for better picture.

\section{References}

1. International Diabetes federation -Facts and figures. The International Diabetic 
federation Diabetes Atlas. 9th ed. 2019. Available from: https://www. idf.org.

2. Unnikrishnan R, Anjana RM, Mohan V. Diabetes mellitus and its complications in India. Nat Rev $\quad$ Endocrinol. 2016;12 (6):357- 370. doi:10.1038/nrendo.2016.53

3. India country report 2019. The International Diabetes Federation Diabetes Atlas. 9th edd. 2019. Available from: www.diabetesatlas.org

4. Pawar SD, Naik JD, Prabhu P, Jatti GM, Jadhav SB, Radhe BK. Comparative evaluation of Indian Diabetes Risk Score and Finnish Diabetes Risk Score for predicting risk of diabetes mellitus type II: A teaching hospital-based survey in Maharashtra. J Family Med Prim Care. 2017;6(1):120- 125 . doi:10.4103/22494863.214957.

5. Joshi SR. Indian Diabetes Risk Score. J Assoc Physicians India. 2005;53:755- 757.

6. Joshi SR, Das AK, Vijay VJ, Mohan V. Challenges in diabetes care in India: sheer numbers, lack of awareness and inadequate control. J Assoc Physicians India. 2008;56:443- 450.

7. Mohan V, Deepa R, Deepa M et al. A Simplified Indian Diabetes Risk Score for Screening for Undiagnosed Diabetic Subjects. J Assoc Physicians India 2005; 53:755-63.

8. Adhikari P, Pathak R, Kotian S. Validation of the MDRF- Indian Diabetes Risk Score (IDRS) in another south Indian population through the Boloor Diabetes Study (BDS). J Assoc Physicians India 2010;58:434- 6.

9. Bala S, Pandve $\mathrm{H}$, Kamala $\mathrm{K}$, Dhanalakshmi A, Sarikonda H. Performance of Indian diabetic risk score as a screening tool of diabetes among women of industrial urban area. J Family Med Prim Care. 2019;8(11):3569- 3573. Published $2019 \quad$ Nov 15. doi:10.4103/jfmpc.jfmpc_799_19.
10. Gupta SK, Singh Z, Purty AJ, et al. Diabetes prevalence and its risk factors in rural area of Tamil Nadu. Indian $\mathbf{J}$ Community Med. 2010;35(3):396- 399. doi:10.4103/0970-0218.69262.

11. Nandeshwar S, Jamra V, Pal DK. Indian diabetes risk score for screening of undiagnosed diabetic subject of Bhopal city. National Journal of Community Medicine 2010; 1:176-7.

12. Chaturvedi M, Pandey A, Javed M, Baiswar R. Validity of Indian Diabetes Risk Score (IDRS) in Population in and Around Agra. J Assoc Physicians India. 2018;66(10):33- 35 . 